\title{
Darwin and the 20-year publication gap
}

\begin{abstract}
Did Darwin delay publishing his theory of evolution by natural selection because he feared an outcry from the establishment? This has been a popular belief, and has been stoked by the fact that although Darwin began formulating the theory in 1837, he did not publish On the Origin of Species until 1859.

Now John van Wyhe, a science historian at the University of Cambridge, UK, says that after a painstaking trawl through the letters, notes and books written by, to or about Darwin, he can rule out the idea once and for all. But van Wyhe's work has irritated several prominent historians, who argue that he has gone too far in downplaying ideas about Darwin's reluctance to publish. "Portraying Darwin as having no feelings or reactions to the outside world warps the biographical picture," says David Kohn, editor of the Darwin Digital Library of Evolution.
\end{abstract}

Darwin scholars have long pondered over the time it took to publish Origin of Species. According to van Wyhe, the idea that Darwin delayed because he was scared to publish a theory that so obviously contradicted religious beliefs about creation has dominated both popular and scholarly accounts of the man for decades.

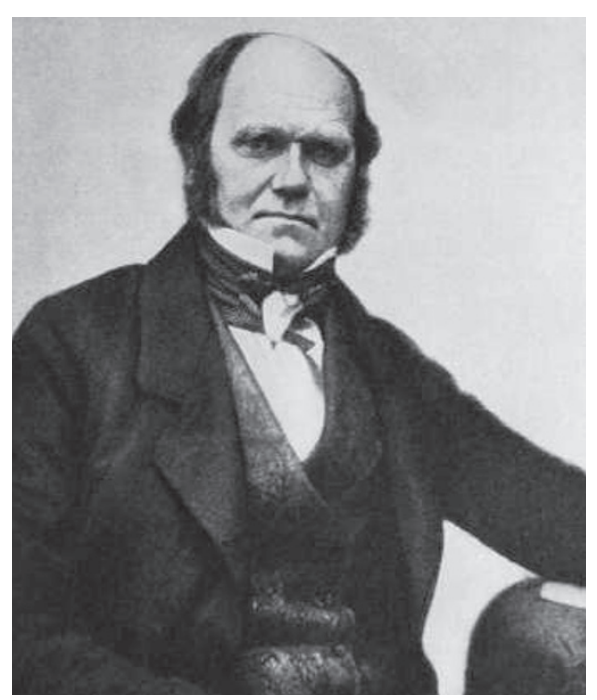

But in a study published this week in Notes and Records of the Royal Society (doi:10.1098/ rsnr.2006.0171; 2007), van Wyhe concludes that there is no direct evidence for the idea, and that it is simply a myth that has passed down the generations without question.

To carry out his study, Van Wyhe searched for the word "delay" in primary and secondary

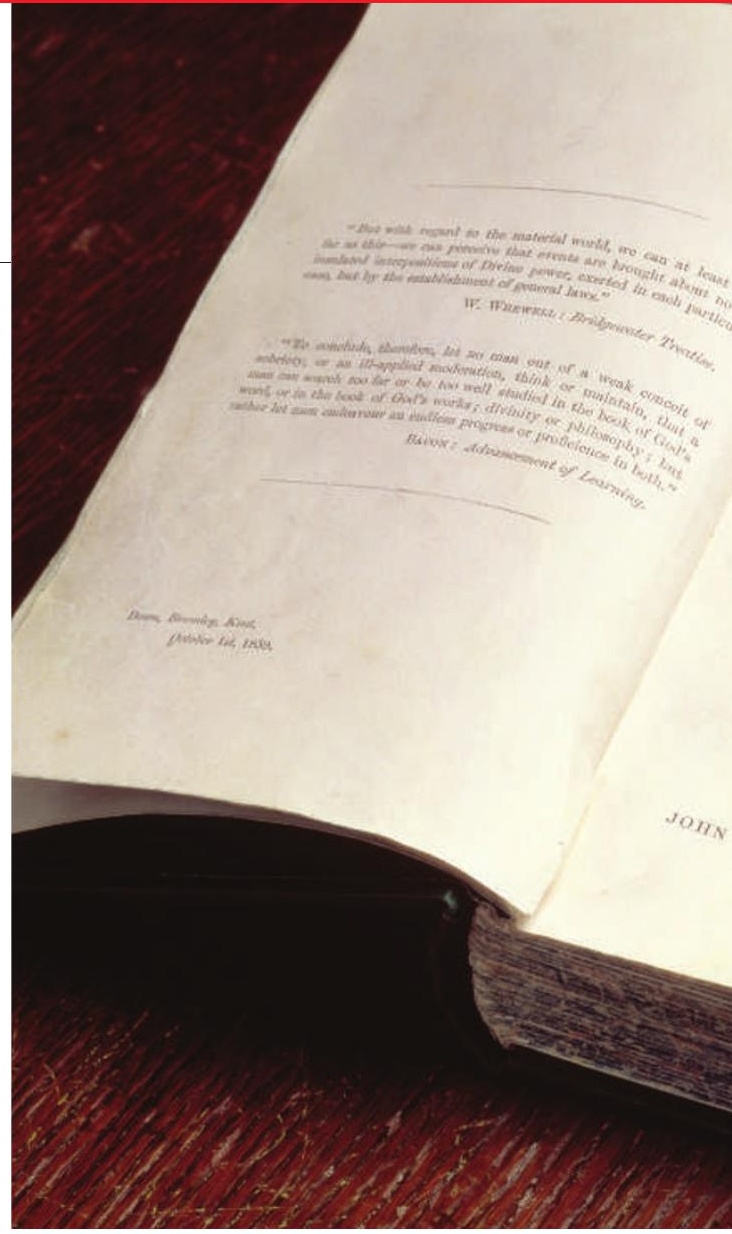

sources covering the period in which Darwin was working on Origin of Species. He says Darwin and those who knew him never unambiguously referred to a delay in publishing, or gave any explanation for the 20-year 'gap'. Indeed, in all the texts on Darwin, he says, the earliest reference to a delay appears in the 1940s. Only in a 1948 popular book, Darwin: Before and

\section{Q.A A vision for Italy's role in space}

Giovanni Bignami, former scientific director of the Italian Space Agency (ASI) and former chair of the European Space Agency's (ESA's) space science advisory committee, was last week nominated as the ASI's next president. Nature asks him about his plans at the ASI, Europe's prospects in space and the art of Galileo Galilei.

\section{What are Italy's main achievements in space?}

The most recent success was the 1996-2002 Italian-Dutch BeppoSax mission dedicated to $\gamma$-ray bursts. A new $\gamma$-ray mission, AGILE, will be launched soon.

\section{And its weaknesses?}

New missions have been delayed, and new concepts crushed, by poor administration hindering the flow of contracts to industry and the scientific community.
What are your plans at the ASI? We need to have a longer vision. Italy hasn't flown a space mission for more than a decade. I want to bring the ASI back to flying satellite missions, both in science and in a variety of applications.

\section{How can Italy live up to its legacy in space?}

Besides hard work and efficiency, this will require balancing a profound European commitment with exploiting the resources of our scientific community in conjunction with industry.

European space research is funded by national agencies such as the ASI, directly and through ESA. Is this mix an obstacle to Europe's competitiveness in space? On the contrary, this is a gift to European nations. Out of the national programmes comes the greater breadth of the European programmes. United we stand, divided we fall.

In its 'Cosmic Vision 2015-2025', ESA has proposed a set of priorities for European space research. Which of the proposed missions do you consider most important? It is most important that Europe now has a vision for its future in space science, from planets to the origin of the Universe. I do not have a scientific preference. That decision will be taken by Europe's scientists. A call for proposals has already hit the streets.

\section{Should Europe join the new} 'race to the Moon'?

Cum grano salis [with a grain of salt].

\section{What about Mars?}

I am a firm supporter of Aurora, ESA's planetary exploration programme. 


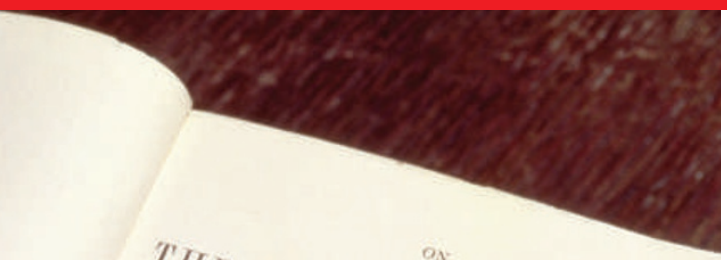

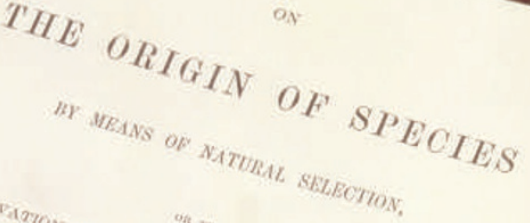

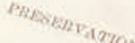

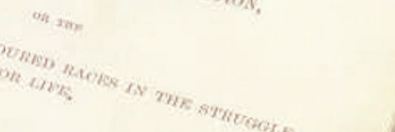

(3)

HARLES DARH

(1)
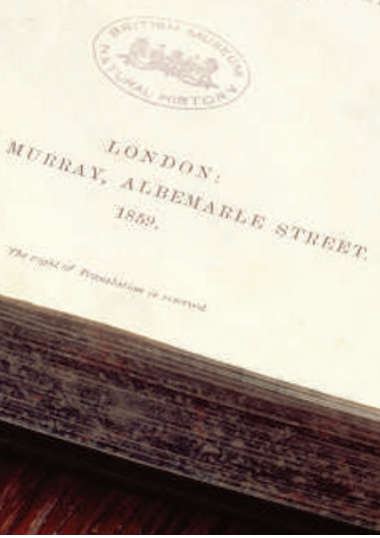

After, in which Robert Clark describes how Darwin was made ill by "an uncertainty that he allowed to haunt him for twenty years", do you see all the elements of the modern story, says van Wyhe.

The historian further argues that in letters to friends, family and colleagues, Darwin continually communicated his belief that species
It has been thought that Charles Darwin (left) delayed publication of his theory of evolution because of concerns over the public's reaction to it.

could change, and that this is inconsistent with the notion that he was keeping his heretical ideas secret during this period. He even paid copiers on at least two occasions to produce early drafts of his species theory.

By documenting exactly what he was doing during the 'gap years', van Wyhe makes the case that Darwin just didn't get down to writing Origin of Species until he had completed other work in hand, including an eight-year study of barnacles. He was determined to build a formidable mass of
"Darwin and those who knew him never unambiguously referred to a delay in publishing." which cultural and social pressures influenced Darwin's decisions may have been overplayed, particularly in the public arena, with less attention being paid to the involved process of scientific discovery. But the consensus in the field is likely to remain that a multitude of factors underpinned Darwin's delay.

Kohn points out that searching for explicit references to a "delay" is a simplistic approach to the problem, and that other factors should be considered. For example, Darwin often criticized religion in his notebooks, which suggests that he would have been aware of the probable implications of his theory for religion. It is hard to see how the absence of specific references to documentation supporting his theory and to solve major stumbling blocks, such as that posed by non-reproductive castes of social insects. This, together with a busy personal life but poor health, filled the years. In other words, Darwin did not postpone publication; he just didn't publish until he was ready. "In my view, this settles the question once and for all," says van Wyhe.

Janet Browne, a science historian at Harvard University in Cambridge, Massachusetts, reckons that van Wyhe's study is a valuable piece of work. "It may not shake the world, but it's an important point to make," she says.

But several Darwin scholars are not convinced. Kohn and others agree that the way in a delay rules out any influence of cultural and societal factors on Darwin's decisions, agrees David Quammen, author of The Reluctant Mr Darwin.

Kohn also points out that in Darwin's later publication The Descent of Man, which applied the theory of evolution to humans, Darwin specifically states in the opening lines that he delayed publishing this tome until he was convinced that the climate was right. It seems likely, therefore, that he would have been aware of the controversy his theories would cause from the outset, and probably avoided discussing humans in Origin of Species for this reason.

Lucy Odling-Smee

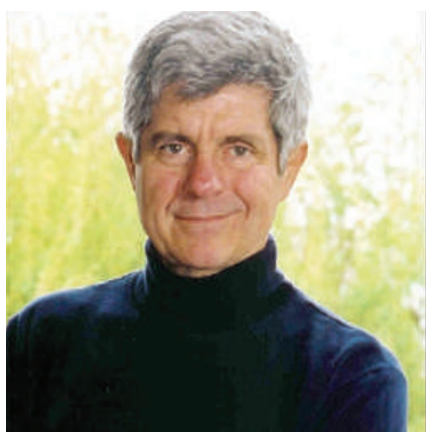

Bignami: wants Italy to return to flying satellite missions.

Its immediate aim is the robotic exploration of Mars. This is a great opportunity for Europe. Aurora also considers manned missions to Mars, albeit in the distant future.

\section{Space exploration requires} strong industrial partners.

\section{Is the balance in Europe between And NASA?} commercial interests and basic research needs in order?

All space missions are being designed, built and flown by industry. European industry needs political support to meet the challenge that is coming from all over the world, in the fields of launchers, satellite production and ground infrastructure. Basic research and commercial interests both represent challenges that can spur European industry to take a leading role in space.

\section{Should Europe reach out for} Russia as a partner in space? Russia is already a partner. Imagine a world where Russia joins ESA. This might look difficult now, but it is potentially very interesting.
Since Italy's very first steps in space more than 40 years ago, it has been collaborating with NASA. I received my space education in the United States, and I will certainly try to increase the quality of the ASI's collaboration with NASA.

\section{Which key questions do you think space scientists will} answer in the next two decades? Three things spring to mind: the nature and origin of dark matter, the observation of gravitational waves from the Big Bang, and discovering a new 'Earth'. All of them require bold, innovative space technologies, which are already at work in precursor missions such as ESA's Gaia, Planck, Herschel and LISA Pathfinder and the NASA/ESA
James Webb Space Telescope. Finding a new Earth, possibly with evidence for life on it, will require the development of new technologies, such as space infrared interferometry.

Galileo Galilei has written some very worldly poems, the longest of which you have translated into English. What has the great scientist achieved in art?

Galileo's achievements in science were born of his post-Renaissance artistic education. He was a skilled draftsman, musician, and of course had a way with words. The Italian novelist Italo Calvino considered him the greatest writer in Italian literature. I remain fascinated by Galileo's genius.

Interview by Quirin Schiermeier. 